\title{
Application of Pickering Emulsified Polymeric Gel System as Water Blocking Agent
}

Tinku Saikiaa, Abdullah S. Sultan ${ }^{\mathrm{a}, \mathrm{b} *}$, Syed R. Hussaini ${ }^{\mathrm{b}}$, Assad Barri ${ }^{\mathrm{a}}$, Nur Iman Khamidya ${ }^{\mathrm{a}}$, Abdulmalek A. Shamsan ${ }^{\mathrm{a}}$, Eassa Abdullah ${ }^{\mathrm{a}}$, Ammar Al-Ramadhan ${ }^{\mathrm{a}}$, Ayman Almohsin ${ }^{\mathrm{c}}$, Mohammed Bataweel ${ }^{\mathrm{c}}$ a Department of Petroleum Engineering, King Fahd University of Petroleum \& Minerals, Dhahran, 31261, Saudi Arabia

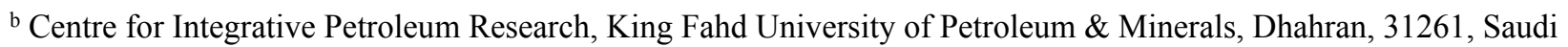
Arabia

${ }^{c}$ Saudi Aramco, EXPEX ARC, Dhahran, Saudi Arabia 


\section{Supplementary Figures}

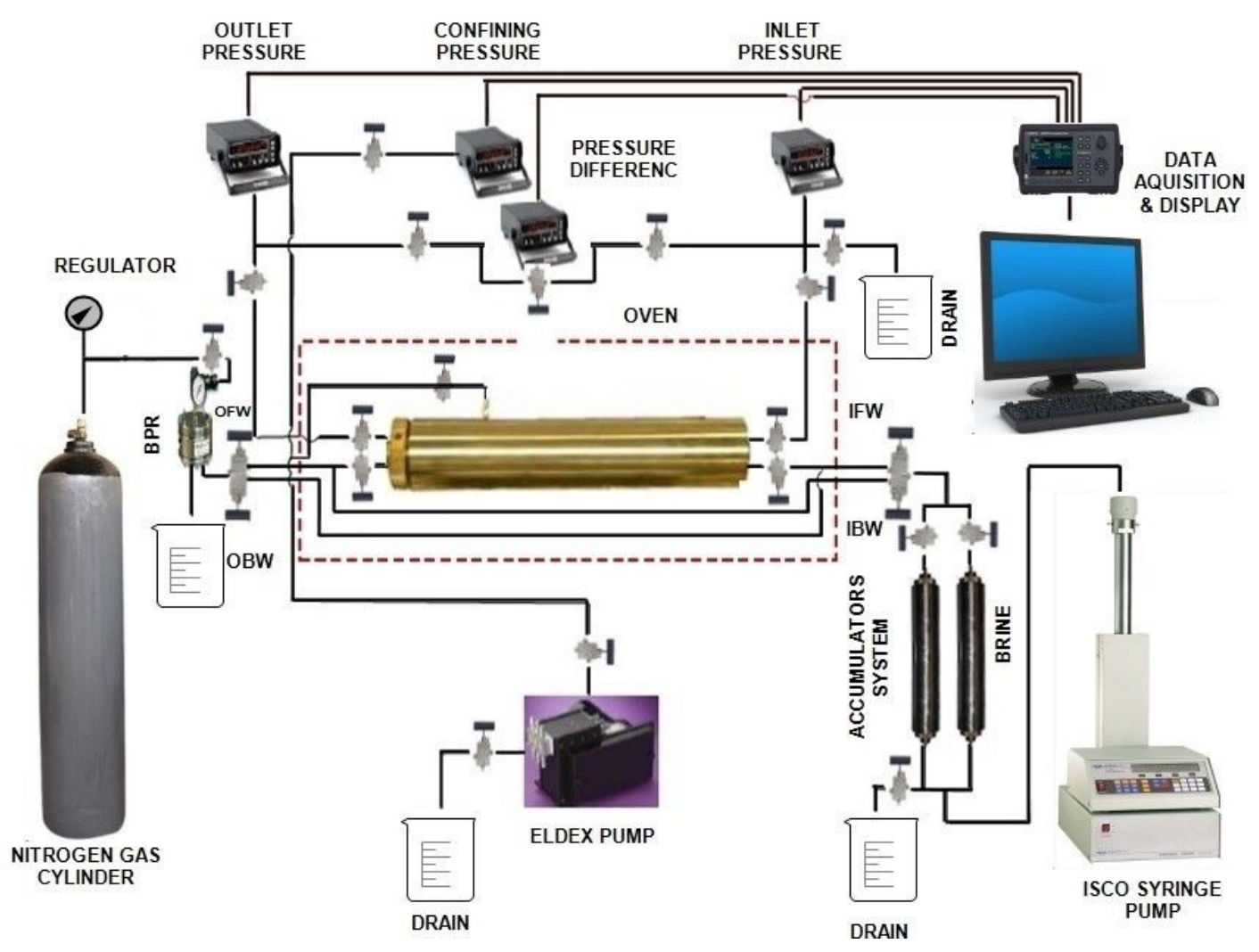

Figure S1: Schematic diagram of AFS 200 (CoreLab) core flooding setup

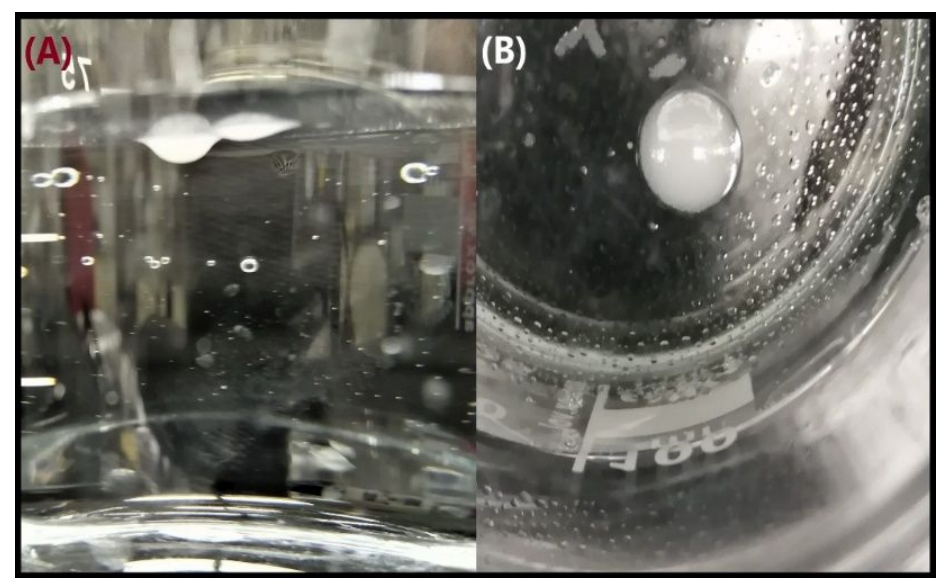

Figure S2: Emulsified polymer gel dilution test to identify the type of emulsion: (A) Front view of invert emulsion (B) Top view of invert emulsion 


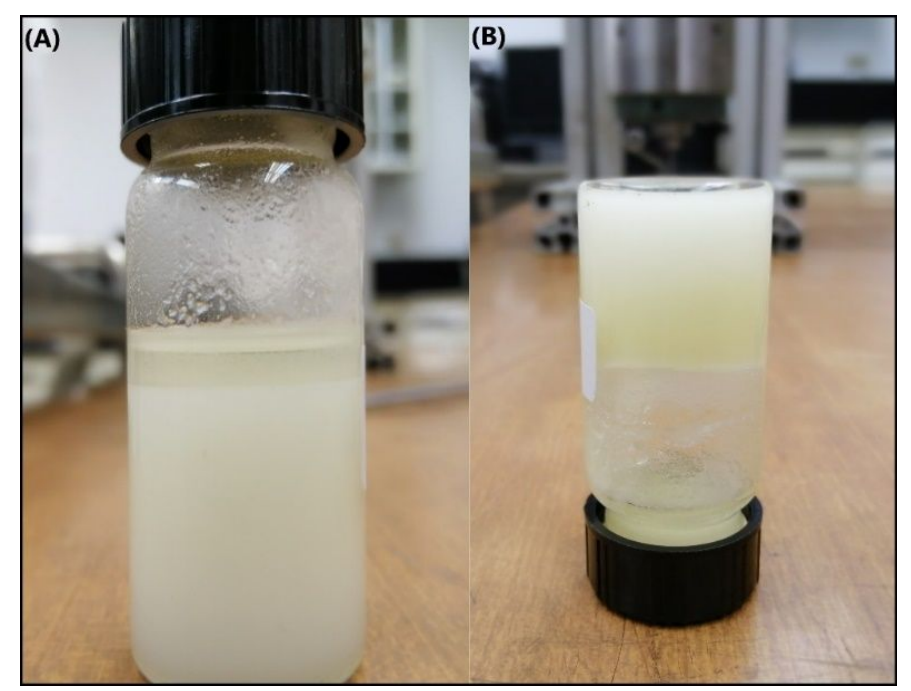

Figure S3: Emulsified polymer gel Inverted bottle test to check the gelation and gel strength (A) Vertical position (B) Inverted position 


\section{Supplementary Tables}

Table S1. Sydnask Gel Strength Code

\begin{tabular}{cl}
\hline Gel Strength Code & \multicolumn{1}{c}{ Gel Description } \\
\hline A & $\begin{array}{l}\text { No detectable gel formed: The gel appears to have the same viscosity as } \\
\text { the original polymer solution }\end{array}$ \\
B & $\begin{array}{l}\text { Highly flowing gel: The gel appears to be only slightly more viscous } \\
\text { than the initial polymer solution }\end{array}$ \\
Clowing gel: Most of the gel flows to the bottle cap by gravity upon \\
inversion \\
Moderately flowing gel: Only a small portion (5-10\%) of the gel does \\
not flow to the bottle by gravity upon inversion (usually characterized as \\
a tonguing gel) \\
Barely flowing gel: The gel can barely flow to the bottle cap and/or a \\
significant portion (>15\%) of the gel does not flow by gravity upon \\
inversion
\end{tabular}

